\title{
An Investigation of 8th Grade Students' Knowledge about Linear Equations
}

\author{
Abdullah Çă̆rn BİBER ${ }^{1}$
}

\begin{abstract}
The purpose of this study was to determine mistakes and misconceptions, if there are any, of the 8th grade students regarding "linear equations". Among the participants of the study were 23 eight grade students from a secondary school located in the North part of Turkey. The study was applied during the second half of 2012-2013 academic years. In the research, four open-ended questions were utilized to achieve the intended goal. According to the results of the study, students have some mistakes and misconceptions regarding determining the points in which the line crosscuts the axis, can not associate linear equation with slope, can not draw the graph of a line the equation of which is given, can not find the equation of a line the graph of which is given, have missing information about the condition of being parallel to the axis and do not conceive the situation completely.

Keywords: Misconceptions, Linear equation, middle school mathematics educations
\end{abstract}

\section{INTRODUCTION}

The mathematic programme of primary school education has been prepared within the framework of five learning areas. These learning areas are determined as numbers, geometry, measuring, probability, statistics and algebra. In mathematics teaching, especially geometry subjects are the lessons which students have prejudices. To eliminate this prejudice and to develop a positive approach against geometry can only be possible with the training which will be given to them. The students' success in geometry in the following years is closely related with the education taken in the early years (Pusey, 2003). According to Maybery (1983), the students' learning of geometric concepts is usually based on memory. The properties, coverage, association and meanings which take place in the geometric statements are not sufficiently taught (Clements and Battista, 1992). Furthermore, development of geometric concepts and reasoning ability comprise a big role in mathematics teaching of students (Clements and Battista, 1992). The Union of National Mathematics Teachers in the U.S.A. (NCTM, 2000), in their book which they determined the basics of school mathematics and standards, they emphasize the importance of geometry and they state that the geometry develops the ability of students for judgment and proving.

Analytical geometry subjects are taking place under sub algebra area in the second level programme of primary school education. The mathematical branch which combines algebra and geometry diciplines, hence investigation of geometry by algebra is called "Analytical Geometry" (Gözen, 2001). Analytical geometry, or coordinate geometry or with its old usage cartesian geometry is the geometry area which uses the basics of algebra; due to the modern development of analytical geometry, it is also called algebric geometry (http://en.wikipedia.org/wiki/Analytic geometry). In the 8th class of primary school curriculum (Ministry of National Education, 2013), analytical geometry includes the acquisitions of "It describes the slope of the line by models", "It determines the relationship between the slope of the line and equation", "It solves the linear equation systems by using the graphs", "It determines the solution set of first degree non-equations with one unknown and shows it on a number line", "It draws the graph of linear non-equations with two unknowns." These acquisitions are taking place under the section of "Equations and Nonequations".

The concepts are essential in the teaching process of analytical geometry. However, the students bring some of their wrong beliefs and experiences with themselves. Besides,

\footnotetext{
1Assoc. Prof., Kastamonu University, Faculty of Education, acbiber@kastamonu.edu.tr
} 
while learning new information, students may structure the concepts wrongly in their minds. All of these lead to learning difficulties and wrong learning. According to Mestre (1989), the students dont come to the class as "empty boards". Instead, they come with the theoires which are being shaped with their daily experiences. They shape those theories actively, and this activity is very important for successful learning. Some of the theories which students compose about what the World is, nevertheless, are uncompleted semi-lines. These are misconceptions. According to the view of Piaget, misconceptions are like structures and added one on another. The misconceptions start as an empty space composing from lack of information. This empty space is filled randomly by the nonqualified teaching given by the lecturer, existing information of the students, and the experiences faced with. The information gathered by the student as filling the empty space is doubtless successful up to a point, but after a certain point, it becomes a misconception (Rowell, Dawson, ve Harry, 1990).

Although the importance of the subject of "linear equation" which is one of the milestones of analytical geometry is emphasized, various studies indicate that the students have difficulty in understanding the subject and have some misconceptions (Birgin, 2006; Zaslavsky, Sela ve Leron, 2002; Stump, 1996). For this purpose, it is emphasized the teaching method of various mathematical subjects such as linear equations, functions and graphs should change corresponding to the modern approaches (NCTM, 2000). In some of the researchs, it is indicated that the misconceptions about linear equation and its graph bring the serious learning difficulties together about functions, limit, derivative and integral (Birgin ve Kutluca, 2006; Turanl1, Keçeli ve Türker, 2007). Therefore, the good learning of linear equation and graphs by the students is very important. On the contrary, the insufficiency of those reseaches is highlighted. Knowing what kind of conception model is developed by the students about the geometric concepts, determining the eisting deficiencies, constructing new structuring in order to overcome these deficiencies are essential.

Based on the above literatue, the current study aimed to determine the learning difficulties, mistakes and misconceptions of 8th graders about the "linear equations". Being in line with the aim, the research questions were

1. What are the mistakes/misconceptions that students posses while drawing the graph of an equation?

2. What are the mistakes/misconceptions that students posses while finding the equation of the graph of a line?

\section{METHODOLOGY}

This study was a case study, in which a researcher can examine a situation within its context, limited by time and activity, and collects detailed information (Yin, 2003). The case that was investigated in this research involves the determination of the mistakes and misconceptions of primary school 8th grade students about the "linear equations".

\section{Study Group}

This study has been performed during the academic year of 2012-2013. Among the participants were 23 eight grade students from a secondary school located in the north part of Turkey.

\section{Data Collection Tool}

Data were collected through four open-ended questions which are aimed to investigate students' learning regarding "linear equations". While preparing the intrunment, related literature was searched, and two experts in the field of mathematics education 
analysed questions in terms of their content validity, prior to application. Whether the problems existing in the prepared data collection tool are convenient or not for the measuring purpose, whether they represent the area which is aimed to be measured; are determined according to the "expert view" (Karasar, 1995).

\section{Data Analysis}

The focus of the analysis was students' responses to the instrunment consicting of four questions. The answer sheets of the students were coded as $\ddot{\mathrm{O}}_{1}, \ddot{\mathrm{O}}_{2}, \ddot{\mathrm{O}}_{3}, \ldots, \ddot{\mathrm{O}}_{23}$, the students' answers were categorized into three groups being true, false and no response. Moreover, the false solutions have also been analysed in detail to investigate the reasons of why those mistakes occured. For each coding category, the frequencies and percentages were given in tables. Students repeated errors in similar questions were evaluated as misconceptions.

\section{FINDINGS}

In this section, the findings and comments are given which have been determined according to the purpose of the research. Each of the questions is analysed individually and the achieved data are presented as tables.

Question 1: Please draw the graph of the line for $y=-x+2$

With this question, it is aimed to determine what kinds of mistakes are done by the students while "drawing the graph of a line the equation of which is given with determining the points intersecting the axis".

The analysis of the answers which the students have given to 1st question is given in Table 1.

Table 1. The Assessment of the Solutions of the Students for Question 1

\begin{tabular}{cccc}
\hline Question 1 & True & False & Unsolvable \\
\hline Frequecy & 10 & 11 & 2 \\
\hline \%* $^{*}$ & $43 \%$ & $48 \%$ & $9 \%$ \\
\hline$($ Perres
\end{tabular}

(* Percentages are approximate values.)

When Table 1 is assessed, it is observed that $48 \%$ of the students solved this question wrongly. When the wrong answers were analysed, it is detected that the students do not know what the points intersecting the axis mean and they do not associate the linear equation and slope, furthermore although they know what the points intersecting the axis mean, but again they do not know how to associate the linear equation and slope. These findings and sample student solutions concerning to each finding is given in Table 2. 
Table 2. The Analysis of the Wrong Solutions in Question 1

\begin{tabular}{|c|c|c|c|}
\hline Findings & $\begin{array}{l}\text { Solutions of wrong samples } \\
\text { supporting the findings }\end{array}$ & Comment & Students \\
\hline $\begin{array}{l}\text { do not know what the } \\
\text { points intersecting the } \\
\text { axis mean and can not } \\
\text { associate the linear } \\
\text { equation and slope }\end{array}$ & $1-$ & $\begin{array}{l}\text { The points intersecting the axis } \\
\text { were determined but since it is not } \\
\text { known what these points mean, } \\
\text { and linear equation and slope can } \\
\text { not be associated; a line with a } \\
\text { positive slope was drawn which } \\
\text { crosses from the points }(0,0) \text { and } \\
(2,2)\end{array}$ & $\begin{array}{c}\ddot{\mathrm{O}}_{2}, \ddot{\mathrm{O}}_{4}, \ddot{\mathrm{O}}_{6}, \ddot{\mathrm{O}}_{7}, \\
\ddot{\mathrm{O}}_{10,}, \ddot{\mathrm{O}}_{23}\end{array}$ \\
\hline $\begin{array}{l}\text { know what the points } \\
\text { intersecting the axis } \\
\text { mean, but can not } \\
\text { associate the linear } \\
\text { equation and slope }\end{array}$ & 5 & $\begin{array}{l}\text { Although it is known what the } \\
\text { points intersecting the axis mean, } \\
\text { the points were detected wrongly, } \\
\text { since the relationship of linear } \\
\text { equation and slope is not known; } \\
\text { a line with a positive slope was } \\
\text { drawn }\end{array}$ & $\begin{array}{c}\ddot{\mathrm{O}}_{11,} \ddot{\mathrm{O}}_{14,} \ddot{\mathrm{O}}_{15}, \\
\ddot{\mathrm{O}}_{17,} \ddot{\mathrm{O}}_{22}\end{array}$ \\
\hline
\end{tabular}

Question 2: Please draw the graphs of the lines for $x=3$ ve $y=3$

With this question, it is aimed to determine what kinds of mistakes are done by the students while "drawing the graphs of lines parallel to the axis".

The analysis of the answers which the students have given to the 2nd question is given in Table 3.

Table 3. The Analysis of the Wrong Solutions in Question 2

\begin{tabular}{cccc}
\hline Question 2 & True & False & Unsolvable \\
\hline Frequency & 4 & 17 & 2 \\
\hline$\%$ & $\% 17$ & $\% 74$ & $\% 9$ \\
\hline
\end{tabular}

(* Percentages are approximate values.)

When Table 3 is assessed, it is observed that $74 \%$ of the students solved this question wrongly. When the wrong answers were analysed, it is detected that the students do not know what the lines parallel to the axis mean and they do not associate the linear equation and slope. These sample student solutions concerning to these findings are given in Table 4 . 
Table 4. The Analysis of the Wrong Solutions in Question 2

\begin{tabular}{|c|c|c|c|}
\hline Findings & $\begin{array}{l}\text { Solutions of wrong samples supporting the } \\
\text { findings }\end{array}$ & Comment & Students \\
\hline \multirow{2}{*}{$\begin{array}{l}\text { do not know } \\
\text { what the lines } \\
\text { parallel to the } \\
\text { axis mean and } \\
\text { can not associate } \\
\text { the linear } \\
\text { equation and } \\
\text { slope }\end{array}$} & $\begin{array}{l}2- \\
2-\end{array}$ & $\begin{array}{c}\mathrm{x}=3, \mathrm{y}=3 \text { lines which are given } \\
\text { in the question were } \\
\text { understood as points }(3,3) \text { in the } \\
\text { coordinate plane, since the } \\
\text { association of linear equation } \\
\text { and slope is not known, a line } \\
\text { with a positive slope was } \\
\text { drawn which crosses from the } \\
\text { points }(0,0) \text { and }(3,3)\end{array}$ & $\begin{array}{l}\ddot{\mathrm{O}}_{2}, \ddot{\mathrm{O}}_{4}, \\
\ddot{\mathrm{O}}_{5}, \ddot{\mathrm{O}}_{6}, \\
\ddot{\mathrm{O}}_{9,}, \ddot{\mathrm{O}}_{23}\end{array}$ \\
\hline & 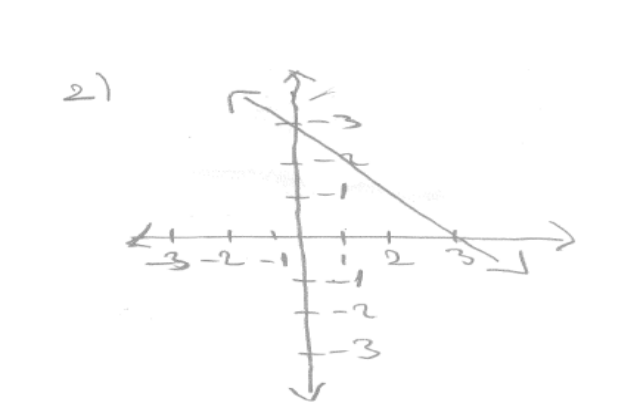 & $\begin{array}{c}x=3, y=3 \text { lines which are given } \\
\text { in the question were } \\
\text { understood as points }(0,0) \text { and } \\
(3,3) \text {, since the association of } \\
\text { linear equation and slope is not } \\
\text { known, a line with a negative } \\
\text { slope was drawn by joining } \\
\text { these points. }\end{array}$ & $\begin{array}{c}\ddot{\mathrm{O}}_{1}, \ddot{\mathrm{O}}_{8,}, \\
\ddot{\mathrm{O}}_{10}, \ddot{\mathrm{O}}_{11}, \\
\ddot{\mathrm{O}}_{12}, \ddot{\mathrm{O}}_{13,} \\
\ddot{\mathrm{O}}_{14}, \ddot{\mathrm{O}}_{15}, \\
\ddot{\mathrm{O}}_{17}, \ddot{\mathrm{O}}_{18}, \\
\ddot{\mathrm{O}}_{22}\end{array}$ \\
\hline
\end{tabular}

It is observed that similar information is required to be used in the solutions of 1st and 2nd questions. When the answers given to the questions by the students were analysed, again similar findings were achieved, for the solution of both of the questions, it was seen that particularly the same students $\left(\ddot{\mathrm{O}}_{2,}, \ddot{\mathrm{O}}_{4}, \ddot{\mathrm{O}}_{6} \ddot{\mathrm{O}}_{11}, \ddot{\mathrm{O}}_{14}, \ddot{\mathrm{O}}_{15}, \ddot{\mathrm{O}}_{17}, \ddot{\mathrm{O}}_{22}, \ddot{\mathrm{O}}_{23}\right)$ repeat the same mistakes.

In these questions, it is seen that the students misconcept the lines intersecting the axis, can not associate linear equation and slope (by benefiting from the equation of the line, they can not determine the line's being with a positive slope, negative slope or parallel to the axis) and deriving from this, make mistakes about drawing the graph of a line the equation of which is given. Since these mistakes are particularly made by the same students in the solutions of the questions which the similar information is required, it is derived that the students have misconceptions in these subjects.

Question 3: Which of these lines $x=4, x=8, y=5, y=8, y=2 x+8, y=3 x$ are parallel to the $x$ axis?

With this question, it is aimed to determine what kinds of mistakes are done by the students while "determining the lines parallel to the axis".

The analysis of the answers which the students have given to the 3rd question is given in Table 5.

Table 5. The Analysis of the Wrong Solutions in Question 3

\begin{tabular}{cccc}
\hline Question 2 & True & False & Unsolvable \\
\hline Frequency & 4 & 18 & 1 \\
\hline$\%$ & $\% 17$ & $\% 78$ & $\% 5$ \\
\hline
\end{tabular}

(* Percentages are approximate values.)

When Table 5 is assessed, it is observed that $78 \%$ of the students solved this question wrongly. When the wrong answers were analysed, it is detected that the students do not know what the "lines parallel to the axis" mean as well as they have wrong information in 
determining whether the lines, equations of which, were given are parallel to the axis. These sample student solutions concerning to these findings are given in Table 6.

Table 6. The Analysis of the Wrong Solutions in Question 3.

\begin{tabular}{|c|c|c|c|}
\hline Findings & Solutions of wrong samples supporting the findings & Comment & Students \\
\hline $\begin{array}{l}\text { do not } \\
\text { know what } \\
\text { the "lines } \\
\text { parallel to }\end{array}$ & $\begin{array}{l}\therefore=2 x+8, \quad y=3 x \\
\text { gem } y=1 \text { pocelerdin }\end{array}$ & $\begin{array}{c}\text { It is thought that all } \\
\text { equations stated as } \\
y=\ldots \text { are parallel to } \\
\text { the } x \text { axis }\end{array}$ & $\begin{array}{c}\ddot{\mathrm{O}}_{1}, \ddot{\mathrm{O}}_{5}, \ddot{\mathrm{O}}_{6}, \ddot{\mathrm{O}}_{7}, \ddot{\mathrm{O}}_{8}, \\
\ddot{\mathrm{O}}_{10} \\
\ddot{\mathrm{O}}_{15}, \ddot{\mathrm{O}}_{16}, \ddot{\mathrm{O}}_{18}, \ddot{\mathrm{O}}_{19}, \\
\mathrm{O}_{20}, \ddot{\mathrm{O}}_{23}\end{array}$ \\
\hline $\begin{array}{l}\text { have wrong } \\
\text { pre- } \\
\text { information }\end{array}$ & $y=2 x+8$ & $\begin{array}{c}\text { Since the } \\
\text { parallelism of } x \text { axis } \\
\text { is asked in the } \\
\text { question, } \text { It is } \\
\text { thought that all } \\
\text { equations stated as } \\
x=\ldots \text { are parallel to } \\
\text { the } x \text { axis }\end{array}$ & $\ddot{\mathrm{O}}_{9}, \ddot{\mathrm{O}}_{11}, \ddot{\mathrm{O}}_{22}$ \\
\hline
\end{tabular}

Question 4: Please write the equation of the lines the graphs of which are given below

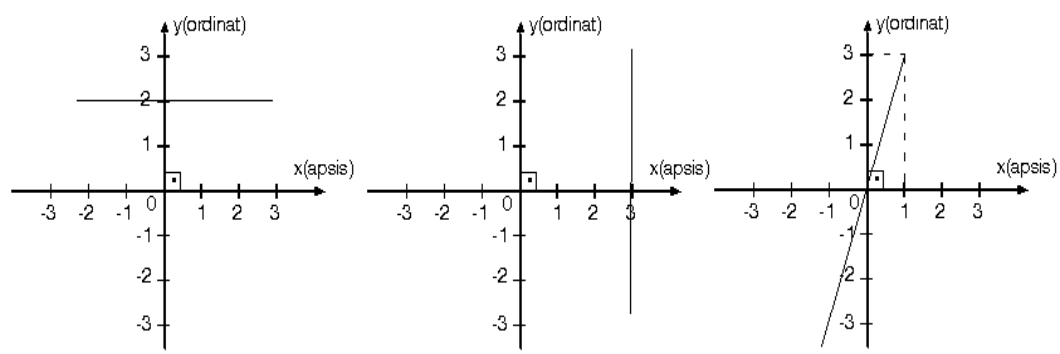

With this question, it is aimed to determine what kinds of mistakes are done by the students while "finding the equation of a line, the graph of which is given".

The analysis of the answers which the students have given to the 4th question is given in Table 7.

Table 7. The Analysis of the Wrong Solutions in Question 4

\begin{tabular}{cccc}
\hline Question 2 & True & False & Unsolvable \\
\hline Frequency & 3 & 14 & 6 \\
\hline$\%$ & $\% 13$ & $\% 61$ & $\% 26$ \\
\hline
\end{tabular}

(* Percentages are approximate values.)

When Table 7 is assessed, it is observed that $61 \%$ of the students solved this question wrongly. When the wrong answers were analysed, it was detected that the students do not have difficulty in finding the equation of the lines which are parallel to the axis, they make mistakes about finding the equation of the lines which are not parallel to the axis, do not know how to find the equation of the lines the graph of which are given. The sample student solutions concerning to these findings are given in Table 8 . 
Table 8. The Analysis of the Wrong Solutions in Question 4

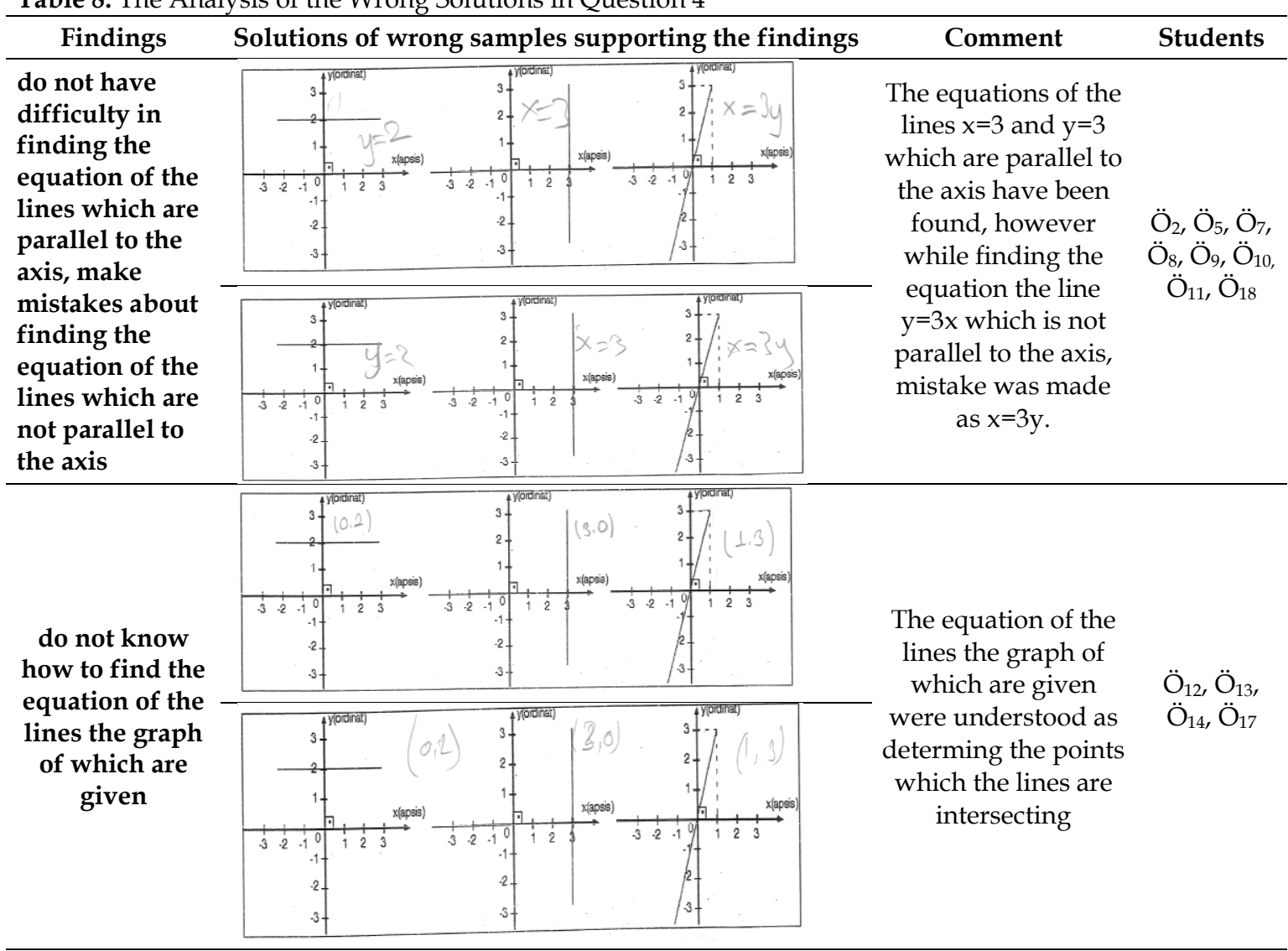

Furthermore, when the solutions of the students who gave wrong answers to the 1st and 4th questions are assessed, it is observed that the students who can not draw the graph of a line the equation of which is given in the 1st question, also can not find the equation of a line the graph of which is given in question 4. (Ö2, Ö7, Ö10, Ö11, Ö14, Ö17)

When the solutions of the students who gave wrong answers to the 3rd and 4th questions are assessed, it is observed that the students who can draw the graph of the lines the equation of which are given and parallel to the axis in the 3rd question (Ö12, Ö13, Ö14, Ö17), can not find the equations of the lines the graph of which are given and parallel to the axis in the 4th question. According to this finding obtained from 3rd and 4th questions, it can be said that the students reach the solution by memorization ragarding drawing the graph of the lines the equation of which is given and parallel to the axis, they make mistakes when they face with a situation which is opposite to the 3rd question, hence they don't fully understand the parallelism to the axis.

In the solutions of 2nd and 3rd questions, similarly it is seen that the information about the lines parallel to the axis should be used. When the answers of the students are analysed, again similar findings have been obtained, it was seen that the students have missing or wrong learnings about the lines parallel to the axis. Since this finding has been obtained particularly in the answers of the same students (Ö1, Ö5, Ö6, Ö8, Ö9, Ö10, Ö11, Ö15, Ö18, Ö22) in the questions which require the use of similar information, indicate that the students have misconceptions about this subject.

\section{RESULTS AND RECCOMENDATIONS}

The solutions of 4 open-ended questions were assessed which have been prepared for this study for 8th class students, it was aimed to detect the mistakes of the students regarding "linear equations" and misconceptions. 
When the solutions for 1st and 2nd questions, which require the similar information to be used in the solution, were analysed; the similar mistakes were done by the same students. The findings obtained from these questions indicate that the students have misconceptions about what the points intersecting the axis mean and also have misconceptions about associating the linear equation and slope. When literature survey is done, it is seen that the mistakes while drawing the graph of a line the equation of which is given usually result form the misconceptions about slope (Clement, 1985; Bell\& Janvier, 1981). In the performed research, it is seen that the students have misconceptions about the positivity and negativity of the slope.

Similary, in the solution of 2nd and 3rd questions that investigate students' knowledge about the lines parallel to the axis should be used, the same students have missing or wrong learnings about the lines parallel to the axis. This situation refers that the students have misconceptions about the lines parallel to the axis. The findings obtained from these questions indicate that some students have tendency to draw a curve the graph of which is increasing under all conditions. It is seen that similar finding has been achieved in a study of Mevarech ve Kramarsky (1997).

The solutions of the students for 3rd and 4th questions have indicated that the students reach the solution by memorization for drawing the graph of the lines the equation of which is given and parallel to the axis, they make mistakes when they face with a situation which is contrary to 3rd question. With the light of the information obtained from these questions, it can be concluded that the students can not fully understand the parallelism to the axis.

When the solutions of the students who gave wrong answers to the 1st and 4th questions are reviewed, it was seen that the students who can not draw the graph of a line the equation of which is given in the 1st question, also can not find the equation of a line the graph of which is given in the 4th question. In a study which was done by Markovits v.d. (1986) for high school level students, similar findings were obtained as in the 4th question. When the wrong answers of these two questions were analysed, it was seen that the students conceive the "linear equation" definition as a single point which a line intersects $($ as $(0,3)$ point or $(3,3)$ ). This situation reveals that the students have misconceptions about linear equation.

With the light of the findings obtained by this study, it can be concluded that the students have misconceptions about the basic acquisition of "linear equations". It is very difficult to change the misconceptions of the students. If there are misconceptions in preinformation of students about the new subjects, those may prevent a true learning and may result new misconceptions. The teachers have essential role for overcoming the misconceptions of the students. The mistakes and misconceptions of the students should be detected and should be corrected before they dont cause any mistakes to their future learnings. For this purpose, the definitons related to the subject should be given in a clear and understandable way during the teaching process. Especially, the teaching of linear equation after the differences between the concepts of point and line are taught would be useful in terms of not leading the misconceptions which have been obtained in this study. While teaching the subject of drawing graph, it is important to emphasize on the relation between the linear equation and slope for the purpose of slope's being well understood and preventing the mistakes and misconceptions about drawing graphs. The taugt concepts should be proved with many examples, similar questions should be solved by the students and it should be checked whether these solutions are correct and the concepts about the subject are well understood or not. While teachin the subject of the lines parallel to the axis, an emphasis on graphs sampling the parallelism on the coordinate plane will be efficient in terms of preventing the students to make mistakes due to memorization. Since the national 
Cumhuriyet International Journal of Education-CIJE

e-ISSN: 2147-1606

Vol 3 (2), 2014, 16 - 25

studies focusing on the mistakes of the primary school students about the linear equations have not been coincided, it is required to carry out similar studies on wider samples. 


\section{REFERENCES}

Bell, A., \& Janvier, C. (1981). The interpretation of graphs representing situations. For the Learning of Mathematics, 2(1), 34-42.

Birgin, O. (2006, September). The Learning Level of Primary School Students about the Slope of the Line and Possible Misconceptions. Announcement presented in 1st National Mathematics Education Student Symposium, Dokuz Eylül University, İzmir.

Birgin, O. \& Kutluca, T. (2006). Sample Material on Computer Based Teaching about the Teaching of Linear Equation. 1st National Mathematics Education Student Symposium, İzmir.

Clement, J. (1985). Misconceptions in graphing. Proceedings of the Ninth International Conference for the Psychology of Mathematics Education, 1, 369-375.

Clements, D. H. \& Battista, M. T. (1992). Geometry and spatial reasoning. In D. Grouws (Ed.). Handbook of Research on Mathematics Teaching and Learning, (pp. 420-464). Reston, VA: National Council of Teachers of Mathematics.

Gözen, S. (2001). Matematics and its Teaching. Evrim Yayınevi.

Karasar, N. (1995). Scientific Teaching Methodology (7th publication). 3A Research Training Consultancy Limited Company.

Markovits, R., Eylon, B. S., \& Brukheimer, M. (1986). Function's today and yesterday. For the Learning of Mathematics, 29(1), 18-28.

Mayberry, J. W. (1983). The van Hiele levels of geometric thought in undergraduate preservice teachers. Journal for Research in Mathematics Education. 14, 58 - 69.

Mevarech, Z. R., \& Kramarsky., B. (1997). From verbal descriptions to graphic representations: Stability and change in students' alternative conceptions. Educational Studies in Mathematics, 32, 229-263.

MEB (2013). Academic Programme of Secondary Shool Mathematics (5th, 6th, 7th, 8th classes). taken from website http://ttkb.meb.gov.tr/ on 20th March 2013.

Mestre, J. (1989). Hispanic and anglo students' misconceptions in mathematics. ERIC Digest. http:/ / www.ericdigests.org/pre-9213/hispanic.htm. Erişim Tarihi: 14.09.2008.

National Council of Teachers of Mathematics (NCTM). (2000). Principles and Standards for School Mathematics. VA: Reston.

Pusey, E.L. (2003). The Van Hiele model of reasoning in geometry: a literature review. Mathematics Education Raleigh. North Carolina State University.

Rowell, A. J., Dawson, C. J., ve Harry, L. "Changing Misconceptions: a challenge to science education", International Journal Science Education, Say1: 12(2), ss. 167-175, 1990.

Stump, S. L. (1996). Secondary Mathematics Teachers' Knowledge of The Concept of Slope. Yayınlanmamış Doktora Tezi. Illinois State University, Illinois.

Turanl1, N., Keçeli, V. \& Türker, N. K. (2007). The Attitudes of Second Class Secondary School Students and their Misconceptions and Common Mistakes about Complex Numbers. Balikesir University Magazine of Natural Science, 9(2), 135-149.

Yin, R. K. (2003). "Case Study Research - Design and Methods", Thousand Oaks, London, New Dehli: Sage Publications.

Zaslavsky, O., Sela, H. ve Leron, U. (2002). Being Sloppy About Slope: The Effect of Changing the Scale. Educational Studies in Mathematics, 49, 119-140. 